\title{
The Safety and Efficacy of Guidezilla Catheter (Mother-in- Child Catheter) in Complex Coronary Interventions: An Observational Study
}

\author{
Prakash Kumara ${ }^{\text {a }}$ Puneet Aggarwal ${ }^{b}$, Santosh Kumar Sinha ${ }^{\text {b, d }}$, Dibbendu Khanra ${ }^{c}$, \\ Mahmodullah Razi ${ }^{\mathrm{b}}$, Awdesh Kumar Sharma ${ }^{\mathrm{b}}$, Ramesh Thakur ${ }^{\mathrm{b}}$, \\ Umeshwar Pandey ${ }^{b}$, Vinay Krishna ${ }^{\mathrm{b}}$
}

\begin{abstract}
Background: Lesion characteristics (anatomy, calcification, tortuosity and angulation), vessel morphology, and lack of support add complexity of coronary intervention. Guidezilla catheter, acting as an extension of guide catheter system (mother-in-child catheter), helps to overcome these complexities by enhancing backup during complex intervention.

Methods: The present retrospective, single-center study included 13,157 consecutive patients who underwent percutaneous coronary intervention (PCI) through both transfemoral and transradial routes from January 2015 to July 2019 at LPS Institute of Cardiology, G.S.V.M. Medical College, Kanpur, Uttar Pradesh, India among which Guidezilla ${ }^{\mathrm{TM}}$ catheter (Boston Scientific, Natick, MA, USA) was used in 156 patients. Study endpoints were target lesion crossing, procedural success, and complications. The clinical, angiographic and procedural data of all 156 patients were evaluated to assess safety and efficacy of Guidezilla extension catheter (GEC).
\end{abstract}

Results: The mean age of the enrolled patients was $61.2 \pm 8.67$ years. Type-C lesion was commonest $(69.9 \%)$ followed by B2 $(22.4 \%)$ and B1 $(7.7 \%)$. The commonest indication for its use was tortuosity $(30.1 \%)$ followed by calcification $(21.1 \%)$, angulation $(18.8 \%)$, chronic total occlusion (17.9\%), distally located lesion $(8.3 \%)$, and anomalous origin of vessel in $3.8 \%$. The right coronary artery $(39.2 \%)$ was most commonly intervened artery followed by left anterior descending (LAD) (30.8\%), left circumflex (LCX) (19.9\%), multivessels $(7.6 \%)$, and saphenous vein graft in $2.5 \%$. The mean depth of intubation was $4.2 \pm 1.9 \mathrm{~cm}$. Mean diameter of stents was $34.2 \pm$

Manuscript submitted September 13, 2019, accepted October 14, 2019

aDepartment of Cardiology, Rajendra Institute of Medical Science, Ranchi, Jharkhand, India

${ }^{b}$ Department of Cardiology, LPS Institute of Cardiology, G.S.V.M. Medical College, Kanpur, Uttar Pradesh, India

'AIIMS Rishikesh, Uttarakhand, India

${ }^{\mathrm{d} C o r r e s p o n d i n g ~ A u t h o r: ~ S a n t o s h ~ K u m a r ~ S i n h a, ~ D e p a r t m e n t ~ o f ~ C a r d i o l-~}$ ogy, LPS Institute of Cardiology, G.S.V.M. Medical College, Kanpur, Uttar Pradesh 208002, India. Email: fionasan@rediffmail.com

doi: https://doi.org/10.14740/cr949
$14.4 \mathrm{~mm}$ while mean length of stents was $31.2 \pm 10.2 \mathrm{~mm}$. Lesions were modified using aggressive pre-dilatation in $87.8 \%$, followed by cutting balloon in $10.9 \%$. GEC was delivered across the lesion using buddy wire technique (9.6\%), balloon-assisted tracking (BAT) in $30.1 \%$, and balloon-assisted sliding and tracking (BLAST) in $4.5 \%$ of patients. Stent implantation was successful in 151 out of 156 patients with success rate of $96.7 \%$. Overall failure rate was $3.3 \%$ which was contributed by extreme tortuosity, angulation, and severe calcification. Guidezilla-associated procedural complication (dissection, stent dislodgement, shaft breakage) were reported in three patients $(1.9 \%)$ who were successfully managed.

Conclusion: Guidezilla system acting as mother-in-child extension catheter is a safe and effective tool which provides additional backup support and increases success rate of PCI for complex coronary lesions.

Keywords: Guidezilla catheter; Mother-in-child extension catheter; Balloon-assisted tracking; Balloon-assisted sliding and tracking; Chronic total occlusion; Percutaneous coronary intervention

\section{Introduction}

With refinements in hardwares and catheters, more complex lesions are being intervened, but these complex lesions (calcification, tortuosity, severe angulation or chronic total occlusion (CTO)) also pose additional problems as delivery of balloon or stent to these target lesions becomes difficult due to various factors like inadequate backup support and non-coaxial alignment of guide catheter. These problems can be circumvented by upsizing guide catheter, using different guide catheter, use of buddy wires, strong support wires, anchoring balloons, deep intubation of guide catheter, or using mother-in-child system [1-3]. The mother-in-child system acts as an extension system of guide catheter which not only gives additional backup support but also facilitates delivery of balloons and stents, and at the same time also ensures minimal trauma to ostium of coronary artery [4]. Among the various commercially available guide extension catheters, Guidezilla ${ }^{\mathrm{TM}}$ extension catheter (GEC), because of its unique design and profile, has increased success rate of complex high-risk percutaneous coronary in- 
tervention (CHIP). As there are limited data regarding its use, the purpose of this study was to describe its safety and efficacy among real world patients through both transfemoral and transradial approaches.

\section{Materials and Methods}

\section{Design}

Between January 2015 and July 2019, 13,157 consecutive patients underwent percutaneous coronary intervention (PCI) through transradial or transfemoral route among which GEC was used in 156 patients at LPS Institute of Cardiology, G.S.V.M. Medical College, Kanpur, Uttar Pradesh, India. Baseline demographics of patients, including clinical (age, sex, clinical presentation and indication for coronary angiogram), angiographic outcome (target lesion, type and character of lesion) and procedural data (type of guiding catheter, guidewire $(\mathrm{GW})$, stent, lesion preparation, depth of intubation of GEC) were recorded. Lesion was classified as type A, $\mathrm{B} 1, \mathrm{~B} 2$ or $\mathrm{C}$ as per the American Heart Association/American College of Cardiology (AHA/ACC) criteria which included length, calcification, chronicity, angulation, and tortuosity [5]. GEC was used when balloon or stent could not be delivered to target lesion due to various technical challenges such as: 1) Anomalous origin of vessel; 2) Angulated take-off of native coronary arteries; 3) Proximal tortuosity of vessel; 4) Calcification; 5) Long lesions; and 6) Inadequate backup support for delivery of balloons and stents. In case of multiple indications, the key one leading to GEC use was considered as primary. Efficacy was defined as successful completion of PCI by deployment of stent at the target lesion. Safety was defined as absence of peri-procedural complications (perforation, dissection, stent dislodgement, and fracture of GEC). Intervention through transradial (TRI) or transfemoral (TFI) route was performed using standard protocol. Most of the procedures were performed through $6 \mathrm{~F}$ guiding catheter except bifurcation lesion and CTO where 7F guide was used. Dual antiplatelet drugs were administered orally before performing PCI. The choice of other drugs, intervention approach, equipment, and technique was left at operator's discretion.

\section{Guidezilla mother-in-child catheter and its delivery}

All cases were performed by using $6 \mathrm{~F}$ Guidezilla ${ }^{\mathrm{TM}}$ II catheter irrespective of guide catheter used. It creates smooth pathway for balloon and/or stent delivery by providing greater flexibility and smooth surface. It comes in working length of 150 $\mathrm{cm}$ and has a platinum iridium helical collar with Z-Glide ${ }^{\mathrm{TM}}$ coating which provides smooth finish and minimizes friction. Because it has two radiopaque marker bands at distal end with a radiopaque collar, this increases visibility which helps in its accurate placement and positioning especially in aorto-ostium of the coronary arteries. The radiopaque tip is soft and flexible, which reduces the risk of vessel damage and complications. GEC was advanced over the GW through Y-connector to intu-
Table 1. Baseline Characteristics of Patients $(n=156)$

\begin{tabular}{ll}
\hline Variable & $\mathbf{N}(\mathbf{\%})$ \\
\hline Age (years) & $61.2 \pm 8.67$ \\
Male/female & $118(75.6) / 38(24.3)$ \\
Hypertension & $52(33.4)$ \\
Diabetes mellitus & $37(23.7)$ \\
Dyslipidemia & $28(17.9)$ \\
Smoking & $39(25)$ \\
STEMI & $40(25.6)$ \\
NSTEMI & $51(32.7)$ \\
UA & $45(28.9)$ \\
CSA & $20(12.8)$ \\
\hline
\end{tabular}

STEMI: ST-segment elevation myocardial infarction; NSTEMI: non-STsegment elevation myocardial infarction; UA: unstable angina; CSA: chronic stable angina.

bate the target lesion in most of cases. In case of moderate tortuosity, it was tracked by using balloon anchoring technique. When it failed, balloon-assisted tracking (BAT) technique was used to negate razor effect of its tip. In refractory cases, balloon-assisted sliding and tracking technique (BLAST) was used to achieve deep intubation of GEC [6]. In cases of calcified lesion, GEC was advanced beyond the lesion and stent was tracked and placed distally. Once successfully parked, GEC was withdrawn proximally into guiding catheter, and stent was carefully pulled to place it across the lesion and deployed. In few cases of bifurcation lesion, GEC was used to facilitate to push balloon to open stent strut of main branch. Before delivery of side branch stent, GEC was removed.

\section{Statistical evaluation}

Statistical analyses were performed using SPSS 19.0 (SPSS Inc., Chicago, IL, USA). All continuous variables were expressed as the mean \pm standard deviation, and categorical data were recorded as percentage.

Transluminal coronary angioplasty (PTCA) was performed in all patients as per current guideline only when there was evidence of ischemia. This was an observational study as Guidezilla was used when stent could not be deployed by conventional technique. PTCA was performed only after obtaining informed consent. Use of Guidezilla catheter is a standard part of PTCA when other method to deliver the stent fails. It is not something out-of-the-box approach.

What we are reporting here is observational findings of Guidezilla catheter to facilitate PTCA when conventional technique to deliver stents failed. PTCA was performed only after obtaining informed consent in all patients.

\section{Results}

Baseline data of the patients is presented in Table 1. The mean 
Table 2. Clinical and Procedural Data of Patients Who Underwent PCI Using Guidezilla Catheter $(n=156)$

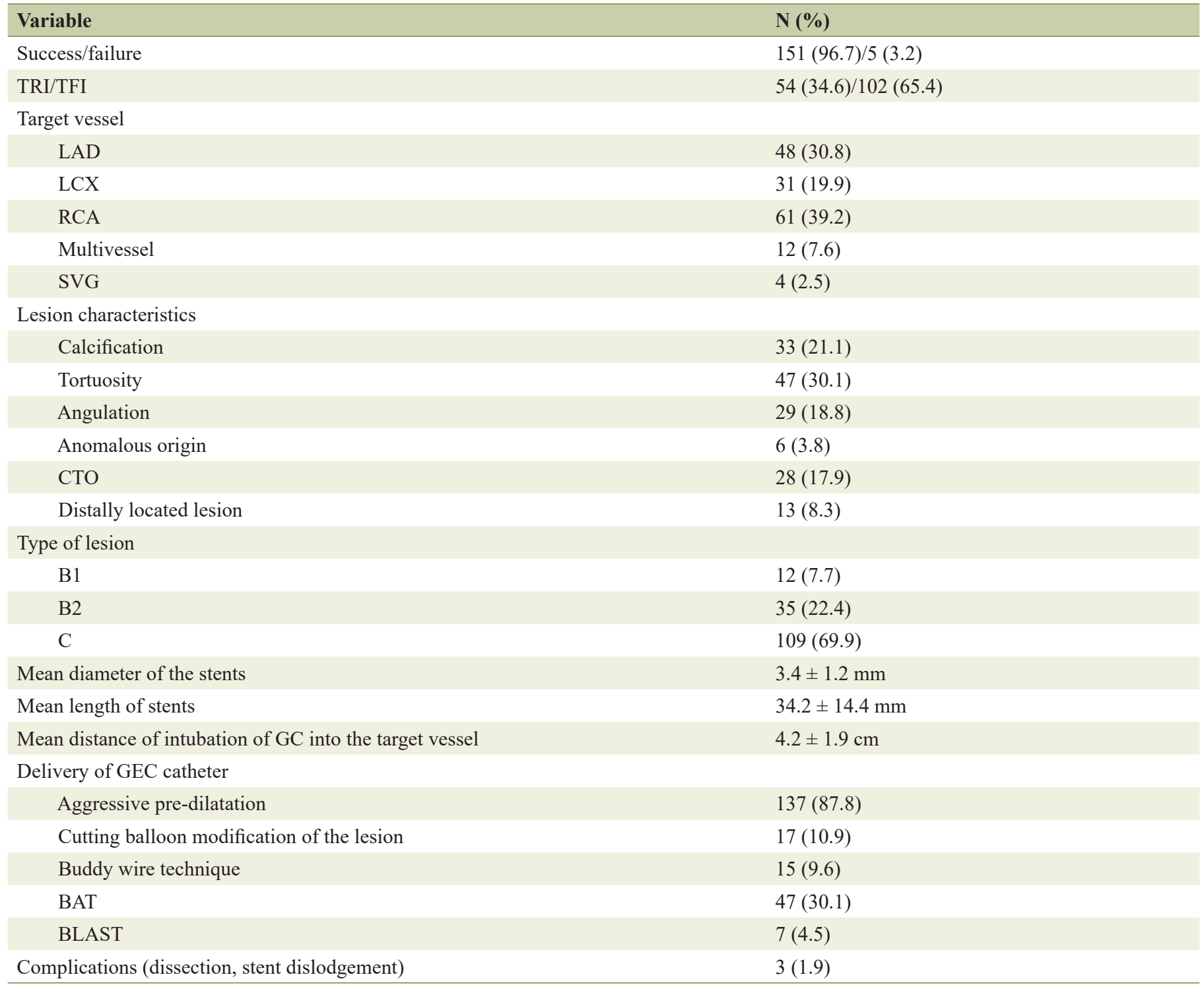

$\mathrm{PCl}$ : percutaneous coronary intervention; TRI: transradial intervention; TFI: transfemoral intervention; LAD: left anterior descending artery; LCX: left circumflex coronary artery; RCA: right coronary artery; SVG: saphenous vein graft; CTO: chronic total occlusion; PCI: percutaneous coronary intervention; GC: Guidezilla catheter; GEC: Guidezilla extension catheter; BAT: balloon anchoring technique; BLAST: balloon-assisted sliding and tracking.

age was $61.2 \pm 8.67$ years with men of $118(76 \%)$ outnumbering the women of $38(24 \%)$. Hypertension was commonest risk factor $(\mathrm{n}=52 ; 33.4 \%)$ followed by smoking $(\mathrm{n}=39$; $25 \%)$, diabetes mellitus ( $\mathrm{n}=37 ; 23.7 \%)$, and dyslipidemia $(\mathrm{n}=28 ; 17.9 \%)$. The commonest clinical presentation was non-ST-segment elevation myocardial infarction (NSTEMI) $(\mathrm{n}=51 ; 32.7 \%)$, followed by unstable angina (UA) $(\mathrm{n}=45$; 28.9\%), ST-segment elevation myocardial infarction (STEMI) $(\mathrm{n}=40 ; 25.6 \%)$, and chronic stable angina $(\mathrm{CSA})(\mathrm{n}=20$; $12.8 \%$ ). Most of the intervention requiring GEC were performed through TFI $(\mathrm{n}=102 ; 64.4 \%)$ and remaining by TRI $(\mathrm{n}=54 ; 35.6 \%)$. Type-C lesion was commonest $(69.9 \%)$ followed by B2 (22.4\%) and B1 (7.7\%). The commonest indica- tion for GEC was tortuosity (30.1\%) followed by calcification (21.1\%), angulation (18.8\%), CTO (17.9\%), distally located lesion $(8.3 \%)$, and anomalous origin of vessel in $3.8 \%$ as shown in Table 2 and Figure 1.

The right coronary artery (RCA) was most commonly intervened (39.2\%; Figs. 2-4) followed by left anterior descending (LAD) (30.8\%; Fig. 5), left circumflex (LCX) (19.9\%; Figs. 6, 7), multivessels $(7.6 \%)$, and saphenous vein graft (SVG; Figs. 8-10) in 2.5\%. The mean depth of intubation was $4.2 \pm 1.9 \mathrm{~cm}$. Mean diameter and mean length of stents was $3.4 \pm 1.2 \mathrm{~mm}$ and $34.2 \pm 14.4 \mathrm{~mm}$ respectively. Lesions were modified using aggressive pre-dilatation in $87.8 \%$ and cutting balloon in $10.9 \%$ of cases. GEC was delivered across the le- 


\section{Indication of various uses of Guidezilla Extension Catheter}

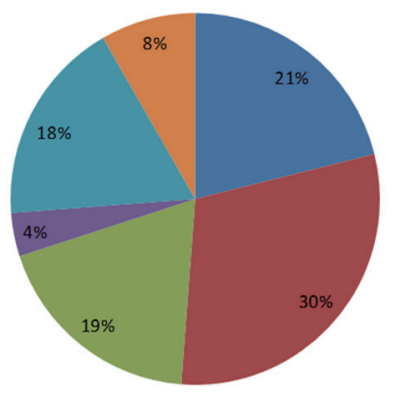

- Calcification

- Tortuosity

Angulation

- Anomalous origin

푸음

Distally located lesion

Figure 1. Indications for various uses of Guidezilla extension catheter in $\mathrm{PCl}$. PCl: percutaneous coronary intervention.

sion using buddy wire technique in $9.6 \%$ (Fig. 9a), BAT (Fig. $9 b$ ) in $30.1 \%$, and BLAST in $4.5 \%$ of cases. Stent implantation was successful in 149 out of 156 patients with success rate of $96.7 \%$. Overall failure rate was $3.3 \%$ which was contributed by extreme tortuosity, angulation, and severe calcification. In two cases, GEC could not be negotiated across the lesion despite all maneuver and procedure were abandoned. GEC-associated procedural complications (dissection, stent dislodgement, shaft breakage) were reported in three $(1.9 \%)$ patients who were successfully managed. In one cases, proximal dissection of RCA occurred with edge of GEC which was stented. Stent stripping, because it had become deformed while crossing the collar segment of GEC, occurred in one patient but fortunately there was no dislodgement as stent remained inside it. GEC along with wire as a whole assembly was removed. Collar fracture of GEC was encountered in one case because of vigorous manipulation for which entire assembly (guide catheter and Guidezilla) was pulled, and procedure was abandoned.

\section{Discussion}

There are limited data regarding safety and efficacy of GEC and most of them had 20 to 30 patients $[7,8]$. This is the largest data of successful use of the GEC incorporating details of 156 patients which showed that it is a useful tool in cases of challenging and complex PCI both through TRI and TFI [5, 9, 10]. TRI of complex lesion is often challenging because delivery of hardwares becomes a limiting factor which can be circumvented using GEC. All intervention through radial route was successful while overall success rate was $96.7 \%$ in our study which is similar as reported by Chan et al [5] and De Man et al [9]. Many of these cases were result of increased backup support of guide catheter as a result of Guidezilla extension, especially in cases where RCA had either acute takeoff angle or shepherd crook type of origin (Fig. 2a, b). Such type of cases were performed using Amplatz guide catheter and GEC which otherwise could not have been possible. This was similarly demonstrated by Takahashi et al [10]. In such scenario, GEC helps in achieving deeper intubation of guide catheter as it glides over GEC. This "rail-roading" effect would not be possible over the GW alone as demonstrated by Farooq et al [11]. Once GEC is deeply intubated, one should be careful about the pressure trace of the artery as it gets pseudodampening. Hence, blood pressure, heart rate and other hemodynamic parameters should be carefully monitored during the procedure to prevent the coronary blood flow being affected by Guidezilla catheter. Sometimes, it can also be used for selective injection of contrast for better visualization of target lesions which therefore minimizes amounts of contrast, especially in patients with compromised renal function as shown by De Man et al [9], although such cohort of patients were not there in our study.

Currently, there are four types of commercially available guide extension catheter: Proxis (St. Jude Medical, MN, USA), Heartrail II (Terumo, Japan), GuideLiner, and Guidezilla. The Proxis catheter is basically a proximal embolic protection device that, apart from being used during routine SVG interventions, can also be used to increase guide support by anchoring the guide catheter by deep intubation and inflation of Proxis sealing balloon [12]. The Proxis device and Heartrial II catheter are $120-\mathrm{cm}$ long which require removal of Y-connector

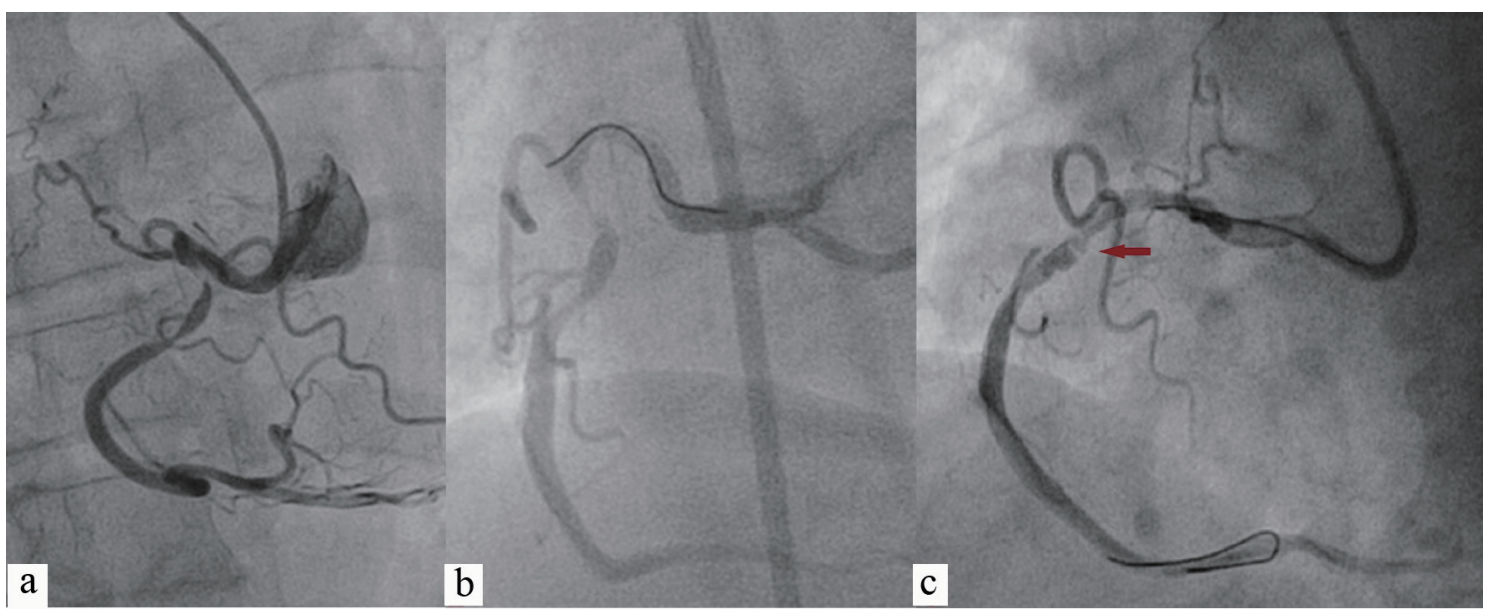

Figure 2. $\mathrm{PCl}$ of RCA having acute take-off origin (a); wired with Sion blue (Asahi, Japan) showing concertina effect (horizontal arrow; b, c). PCl: percutaneous coronary intervention; RCA: right coronary artery. 


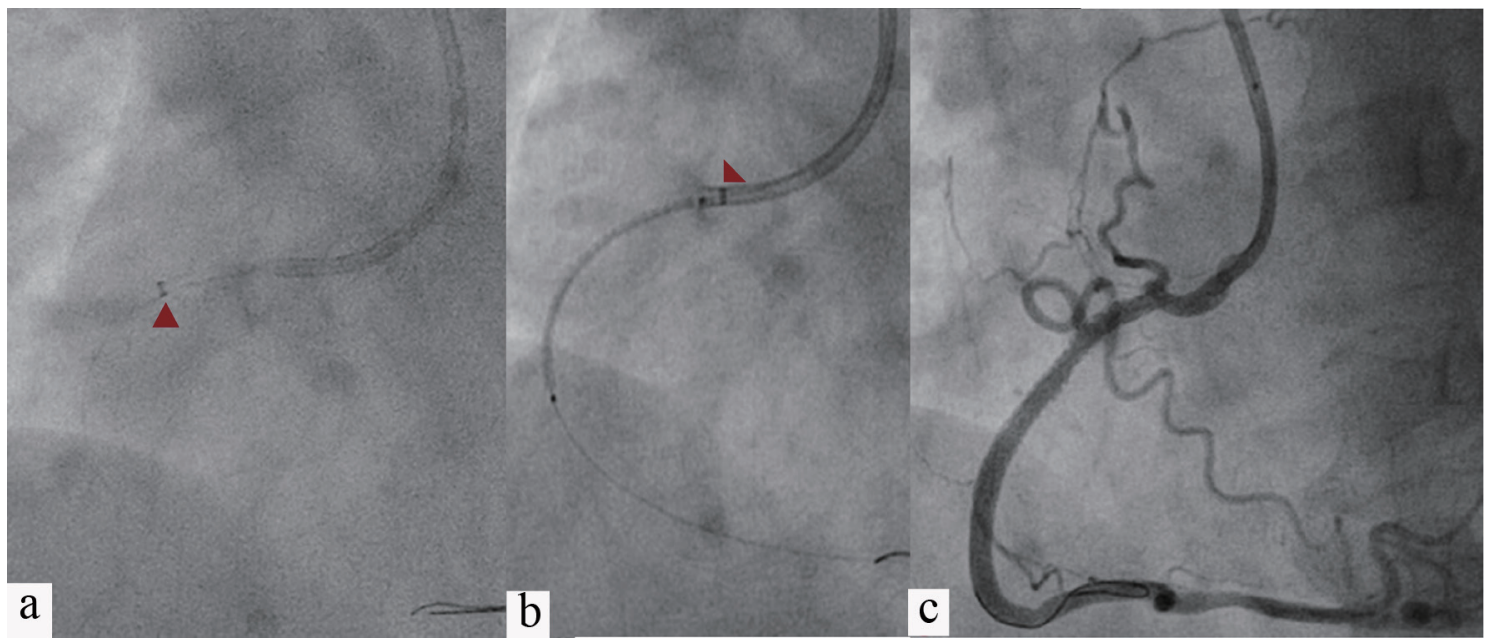

Figure 3. Guidezilla catheter was extended up to mid-RCA (red arrowhead; a); $3.5 \times 38$ Endeavour Resolute (Zotarolimus-eluting stent, Medtronic, CA, USA) was positioned across the lesion after pulling Guidezilla into guiding catheter (red arrowhead; b); Lesion was stented after deploying stent at 14 atm pressure showing TIMI 3 flow (c). RCA: right coronary artery; atm: atmospheric pressure; TIMI: thrombolysis in myocardial infarction.

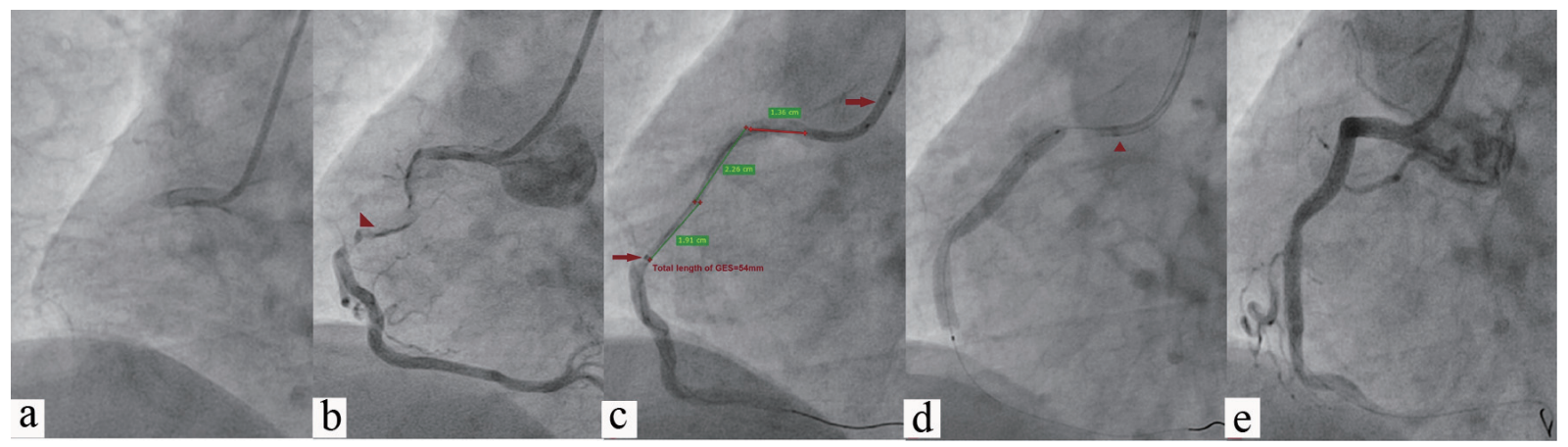

Figure 4. Chronic total occlusion of RCA (a); It was wired with Fielder XT with caravel microcatheter support (Asahi, Japan) (b); GEC was pushed beyond the lesion with balloon anchoring technique (54 mm, red arrowhead; c); $3.5 \times 42$ Supralimus Grace (Sirolimus-eluting stent, Sajahanand Medical, Gujarat, India) was positioned across lesion after pulling Guidezilla into guiding catheter (red arrowhead; d); Lesion was stented after deploying stent at 14 atm pressure showing TIMI 3 flow (e). RCA: right coronary artery; GEC: Guidezilla extension catheter; atm: atmospheric pressure; TIMI: thrombolysis in myocardial infarction.

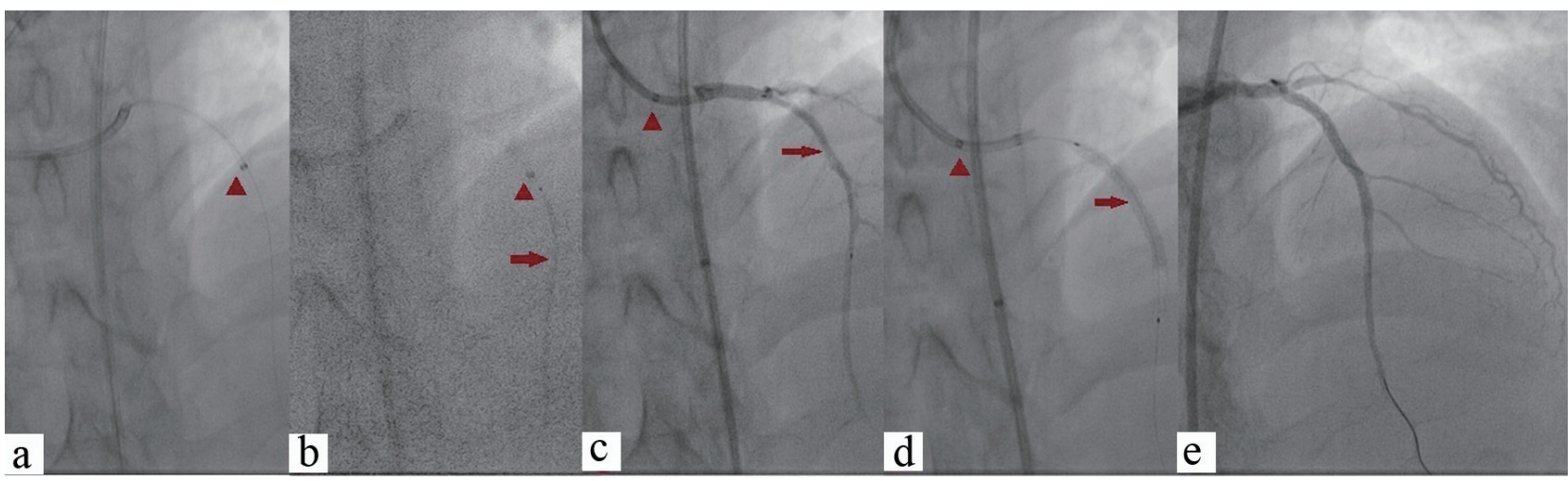

Figure 5. Chronic total occlusion of ostial LAD which was wired with Conquest-Pro 12 with caravel microcatheter support. Lesion was predilated and GEC was pushed beyond the lesion (red arrowhead; a, b); $3.5 \times 42$ Supralimus Grace was positioned across the lesion (red arrow; b, c) after pulling Guidezilla into guiding catheter (red arrowhead; c, d); Lesion was stented at 14 atm pressure showing TIMI 3 flow by pulling it further and properly positioned across the lesion (d, e). LAD: left anterior descending; GEC: Guidezilla extension catheter; atm: atmospheric pressure; TIMI: thrombolysis in myocardial infarction. 


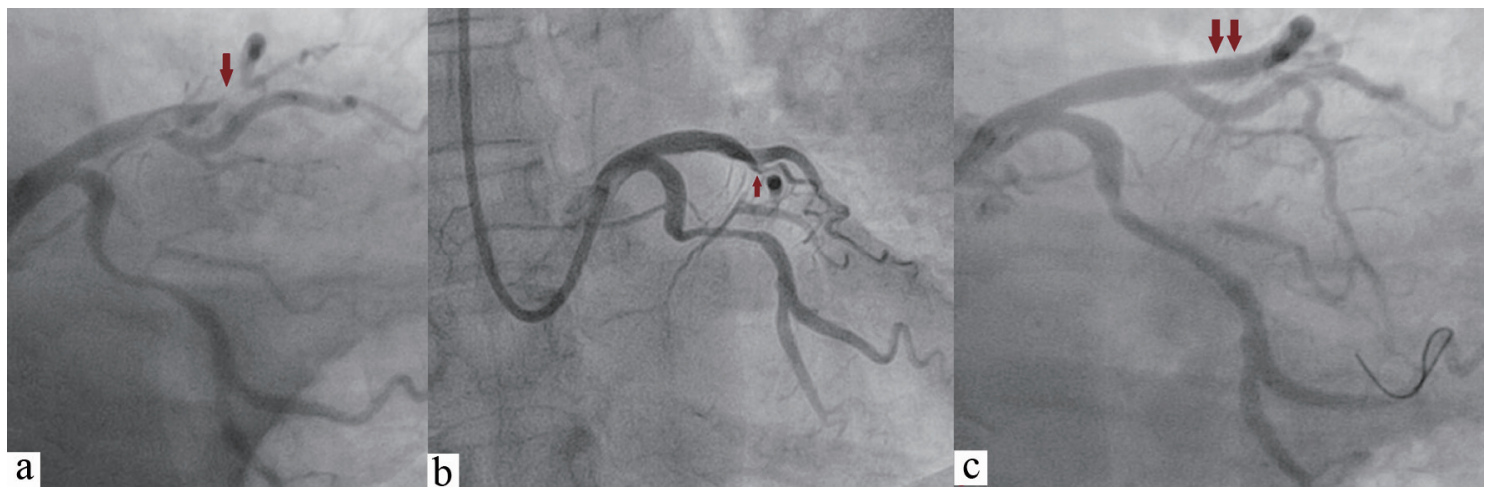

Figure 6. Tortuous diffuse lesion of LCX along with focal lesion of LAD (red arrow; a, b); LAD was stented with $3.5 \times 18 \mathrm{~mm}$ Endeavour Resolute at $13 \mathrm{~atm}$ pressure achieving TIMI 3 flow (double arrow; c), and LCX was wired with Sion blue wire (c). LCX: left circumflex; LAD: left anterior descending; atm: atmospheric pressure; TIMI: thrombolysis in myocardial infarction.

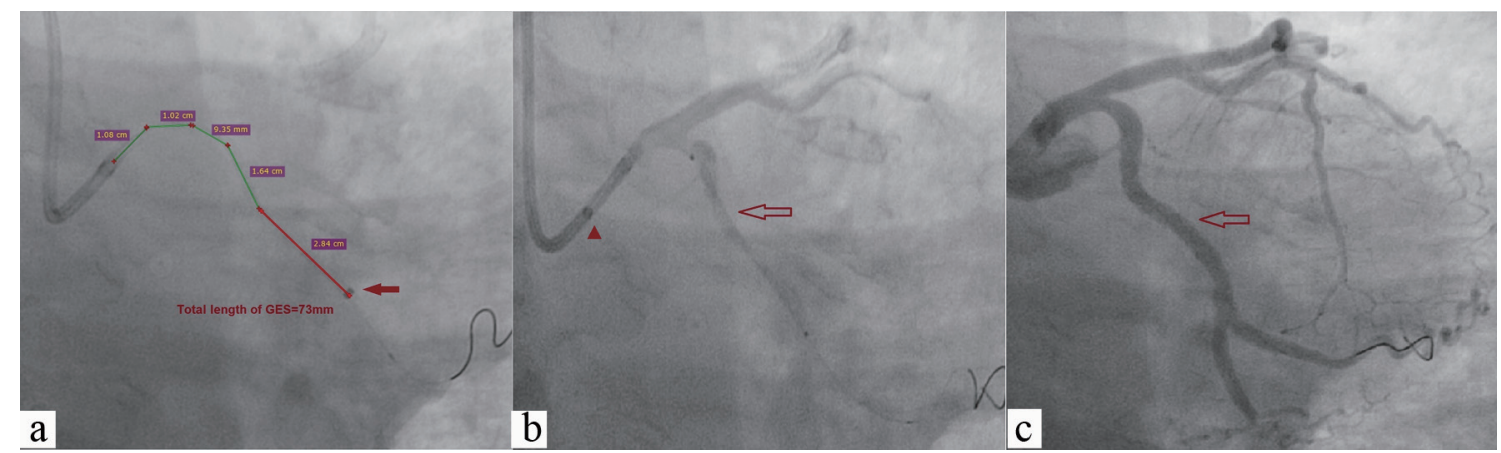

Figure 7. After adequate predilatation, GES was pushed beyond the lesion $(73 \mathrm{~mm}$, red arrow; a); $3.5 \times 46$ Supralimus Grace stent was positioned across the lesion after pulling Guidezilla into guiding catheter (red arrowhead; b); Lesion was stented after deploying stent at 14 atm pressure showing TIMI 3 flow (c). GEC: Guidezilla extension catheter; atm: atmospheric pressure; TIMI: thrombolysis in myocardial infarction.

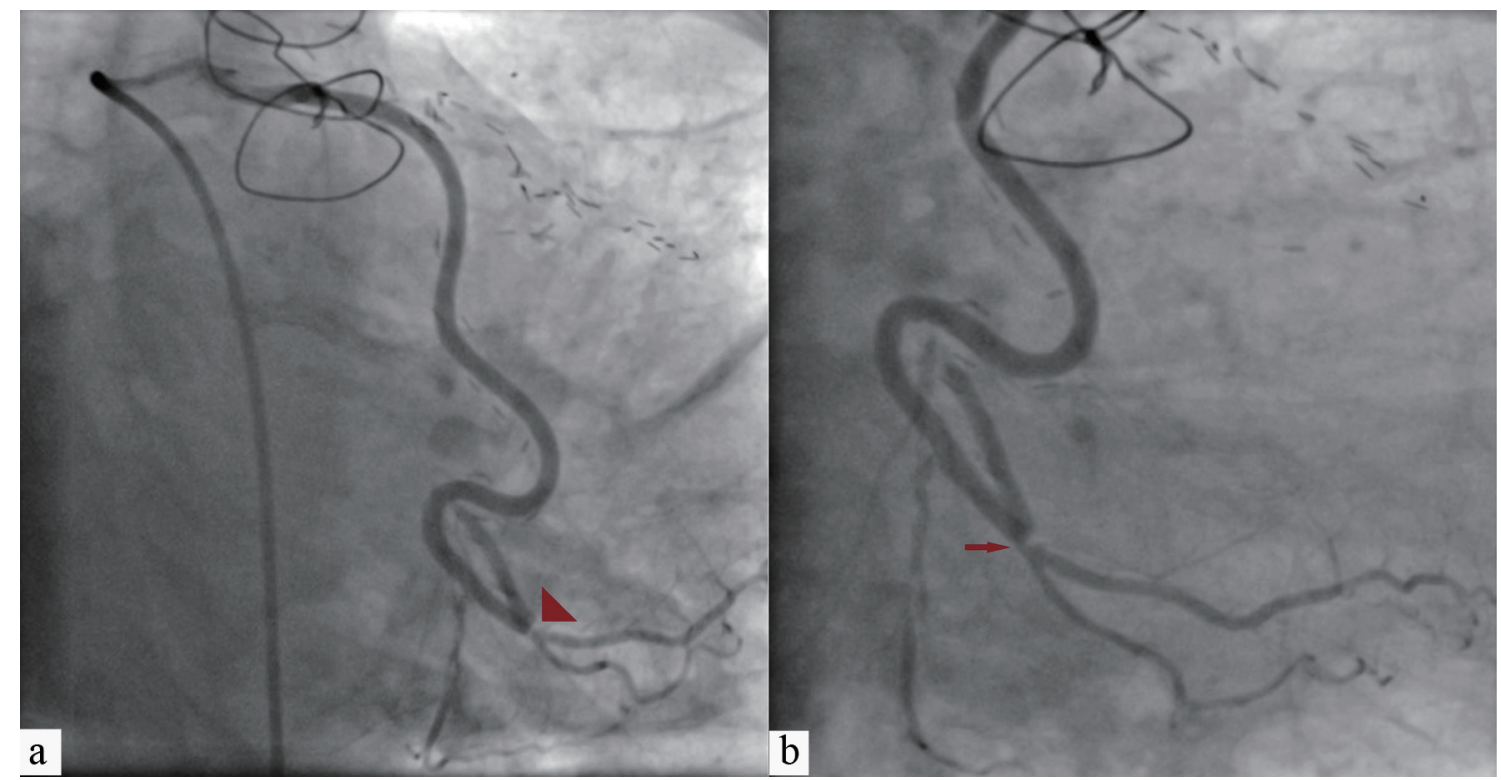

Figure 8. Critical stenosis of SVG to obtuse marginal branch of LCX at anastomotic site in a post-CABG patient who presented with stable angina of CCS class III (red arrowhead, a; red arrow, b). SVG: saphenous vein graft; LCX: left circumflex; CABG: coronary artery bypass graft; CCS: Canadian Cardiovascular Society. 


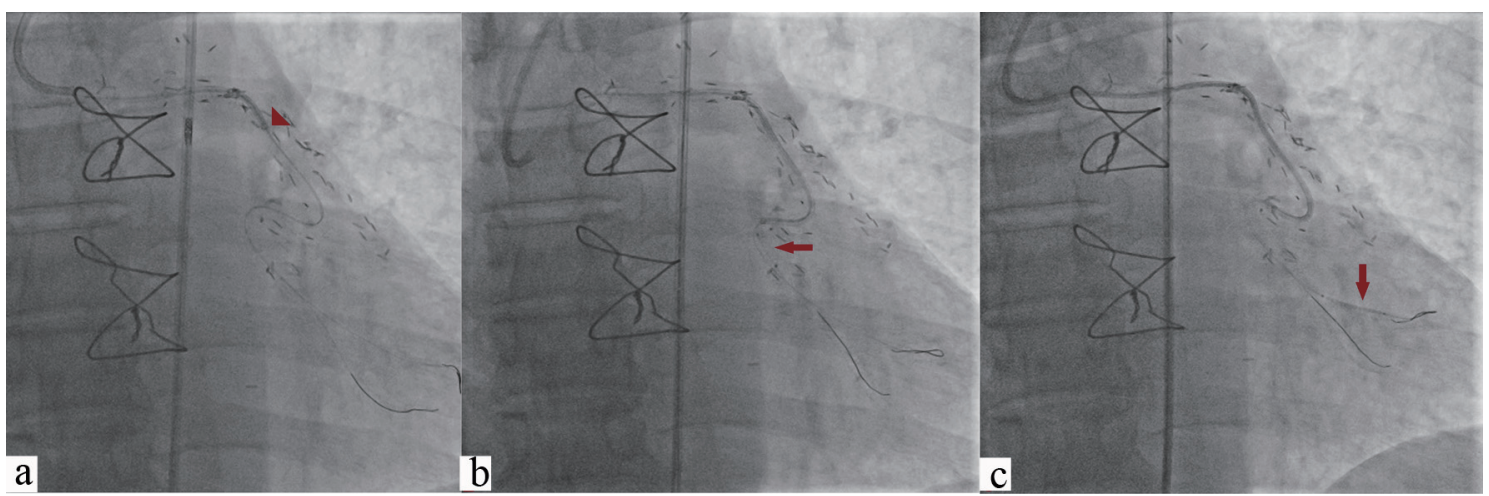

Figure 9. Lesion was wired using Sion blue wire and Guidezilla (red arrowhead) was advanced using buddy wire technique (a); Great difficulty was encountered to push GES which was further advanced with $2.5 \times 10 \mathrm{~mm}$ sprinter legend balloon (red horizontal arrow, Medtronic, CA, USA) using BAT (b); $3 \times 18 \mathrm{~mm}$ Endeavour Resolute stent (vertical arrow) was pushed beyond lesion by keeping buddy wire to garner adequate support (c). GEC: Guidezilla extension catheter; BAT: balloon-assisted tracking.

before their introduction into mother guide. Being $5 \mathrm{~F}$ in calibre, they provide telescoping of guide catheter. These devices need more caution in the cases of acutely angulated vessel or lesion requiring intubation into LAD or LCX as it may undergo kinking. Moreover, their data regarding these scenarios is lacking [13]. GuideLiner V3 catheter (Vascular Solutions, MN, USA) is another guide catheter extension system (GCES) whose distal end is tubular, and being flexible it can be deeply advanced into vessels, thereby providing support without need to disconnect it from the mother guide.

The Guidezilla has a smaller outer diameter $(1.68 \mathrm{~mm})$ and bigger inner luminal diameter $(1.45 \mathrm{~mm})$ than contemporary GuideLiner catheter $\left(0.057^{\prime \prime}\right.$ vs. $\left.0.056^{\prime \prime}\right)$. Because of its unique design and having smaller external diameter, $6 \mathrm{~F}$ mother guide can easily accommodate a 6F Guidezilla catheter, as a result of which it can be easily pushed deep down into artery because outer diameter reduces its interference with mother guide. It has $34 \%$ more pushability, $96 \%$ less frictional force, and $13 \%$ more backup support than GuideLiner catheter. It has more room for deliverability of hardwares because of larger inner diameter.

In our study, calcification and tortuosity contributed near- ly $50 \%$ of indications for its application, primarily to achieve deep intubation to garner more support (Figs. 2, 4, 6-10). Stiff-yet-flexible stainless steel hypotube shaft of Guidezilla catheter provides exceptional pushability and kink resistance while advancing it beyond the tip of mother guide. It has been demonstrated by Takahashi et al [10] using in-vitro model that mere $5 \mathrm{~mm}$ protrusion of $5 \mathrm{~F}$ child catheter beyond tip of mother guide gives significantly greater support than that provided by $7 \mathrm{~F}$ guide catheter alone. The mean depth of intubation in our study was $42 \pm 19 \mathrm{~mm}$ (minimum for ostial lesion of LCX, and maximum $92 \mathrm{~mm}$ for SVG graft) (Fig. 10c), which is similar to that reported by Chan et al [5] and Dursun et al [14] though the longest intubation depth is $120 \mathrm{~mm}$ as reported by Ma et al [15]. Much deeper intubation of Guidezilla device may cause entire segment to prolapse outside ostium of coronary artery, impairing withdrawal of device, and with loss of co-axiality.

In cases where difficulty was felt to advance the Guidezilla catheter to the appropriate location for sufficient backup support, several techniques could be used: 1) Buddy wire technique, which uses another wire to stabilize Guidezilla and increase support (Fig. 9a); 2) Anchoring balloon technique, in which a balloon is deployed distal to the target vessel in a

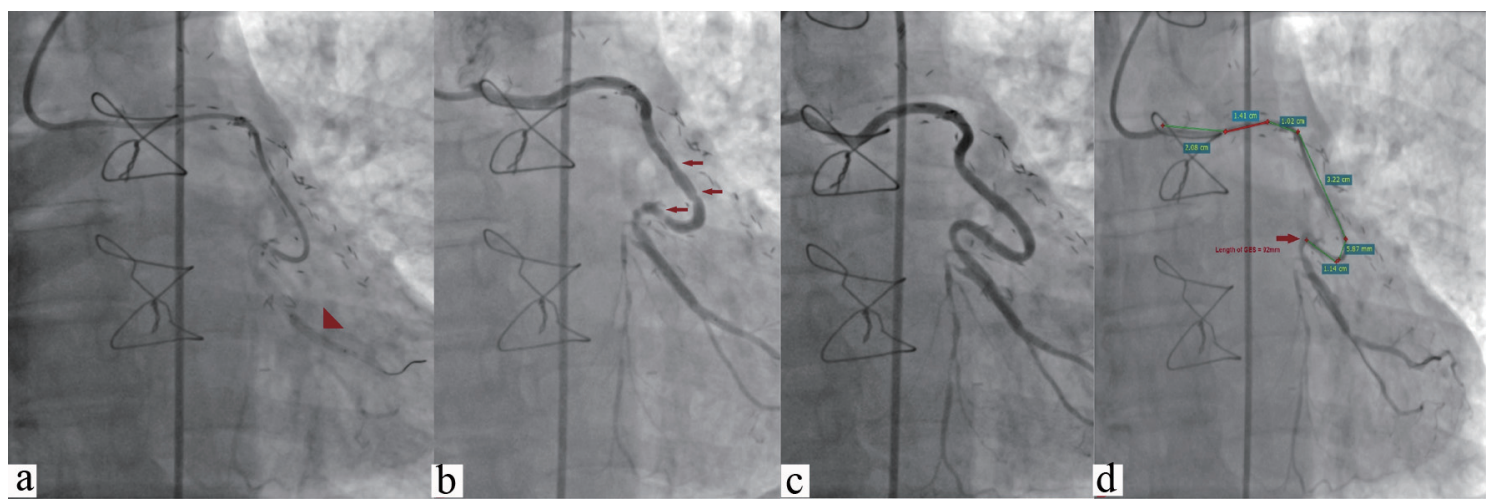

Figure 10. Stent was pulled to position across the lesion after removing buddy wire and deployed at 13 atm pressure (arrowhead) (a); TIMI 3 flow was achieved along with concertina effect (multiple horizontal arrows) after withdrawing GEC (b); Smooth flow after removing the wire which removed concertina effect which was wire bias effect (c); Deep intubation of Guidezilla catheter (92 $\mathrm{mm}$ ) (d). atm: atmospheric pressure; GEC: Guidezilla extension catheter; TIMI: thrombolysis in myocardial infarction. 
small branch or in a stent that was previously placed at another vessel and dilated at low pressure while simultaneously and carefully pushing the Guidezilla catheter (Fig. 9b); 3) Lesion modification followed by BAT; and (d) BLAST in refractory cases. All of these methods were used in our study to achieve positive results (Table 2). In certain lesions where segment was distorted and calcified, GEC was advanced much beyond the target segment in order to get strong support force and unhindered track of stent (Figs. 4a, 5a, 5b, 7a).

Guidezilla catheter also facilitates intervention of CTO lesions in many ways. It can assist initial wiring of the lesion, advancement of micro-catheter (Finecross, Caravel), balloon, and delivery of stent. In our study, GEC was used in five cases for advancing Caravel microcatheter (Ashahi, Japan), balloon crossing in 11 cases, and stent delivery in 12 cases among all CTO interventions. Its another novel use may be in reverse controlled antegrade and retrograde subintimal tracking (reverse CART), as described by Mozid et al [16], although they used GuideLiner catheter instead of Guidezilla. It shortens the distance between point of retrograde GW re-entry and tip of antegrade guiding catheter, though in our study, such cases were none.

GEC-related peri-procedural complications were proximal dissection of the RCA requiring stenting, stent stripping, and collar fracture of Guidezilla, which were encountered in one case each. This is similar to that reported by Waggoner et al [17]. Stent stripping probably occurred due to vigorous manipulation at the proximal junction transition as stainless steel collar of the Guidezilla is not as flexible as the polymer collar of the GuideLiner. In such circumstances, it is always better to pull the whole assembly along with unimplanted stent.

Farooq et al [11] reported about potential risk of damage to bulky stents as they enter the collar and advised using lowprofile stents with the GES, avoiding ones more than $4 \mathrm{~mm}$ in diameter, though 16 patients $(10.2 \%)$ had received $4-m m$ stent in our study with no complication. Our data was retrospectively obtained from a single centre having small sample size, and accordingly native bias cannot be negated. So, larger study is warranted to further investigate our findings.

\section{Conclusions}

Guidezilla use was associated with a high success rate with no major complications which facilitates complex PCI through both transradial as well as transfemoral route. It is non-inferior to the other three guide extension catheters across all spectrum of PCI.

\section{Acknowledgments}

None to declare.

\section{Financial Disclosure}

None to declare.

\section{Conflict of Interest}

None to declare.

\section{Informed Consent}

Informed consent was obtained from all the patients prior to the procedure as all patients were admitted in our hospital.

\section{Author Contributions}

All authors made substantial contributions to the conception or design of the work, and the acquisition, analysis, or interpretation of data for the work; drafting the work or revising it critically for important intellectual content; gave final approval of the version to be published, and agreed to be accountable for all aspects of the work in ensuring that questions related to the accuracy or integrity of any part of the work are appropriately investigated and resolved.

\section{References}

1. Di Mario C, Ramasami N. Techniques to enhance guide catheter support. Catheter Cardiovasc Interv. 2008;72(4):505-512.

2. Saeed B, Banerjee S, Brilakis ES. Percutaneous coronary intervention in tortuous coronary arteries: associated complications and strategies to improve success. J Interv Cardiol. 2008;21(6):504-511.

3. Von Sohsten R, Oz R, Marone G, McCormick DJ. Deep intubation of 6 French guiding catheters for transradial coronary interventions. J Invasive Cardiol. 1998;10(4):198202.

4. Duong T, Christopoulos G, Luna M, Christakopoulos G, Master RG, Rangan BV, Roesle M, et al. Frequency, indications, and outcomes of guide catheter extension use in percutaneous coronary intervention. J Invasive Cardiol. 2015;27(10):E211-215.

5. Chan PH, Alegria-Barrero E, Foin N, Paulo M, Lindsay AC, Viceconte N, Di Mario C. Extended use of the GuideLiner in complex coronary interventions. EuroIntervention. 2015;11(3):325-335.

6. Sinha SK, Tripathi S, Rekwal L, Singh AK, Abhishekh NK. Balloon Assisted Sliding and Tracking of GuideLiner Catheter (BLAST-G) to successfully deliver stent in a calcified, tortuous lesion: case report. Folia Cardiologica. 2018;13(3):247-251.

7. Chen CY, Huang YY, Tang L, Hu XQ, Fang ZF, Zhou $\mathrm{SH}$. Guidezilla extension catheter for percutaneous interventional therapy of complex lesions via a transradial approach: Case series from a single-center experience. Cardiol J. 2018;25(2):171-178.

8. Ma J, Hou L, Qian J, Ge L, Zhang F, Chang S, Xu R, et al. The safety and feasibility of guidezilla catheter in complex coronary interventions and an observational study. 
Medicine (Baltimore). 2017;96(40):e8172.

9. de Man FH, Tandjung K, Hartmann M, van Houwelingen KG, Stoel MG, Louwerenburg HW, Basalus MW, et al. Usefulness and safety of the GuideLiner catheter to enhance intubation and support of guide catheters: insights from the Twente GuideLiner registry. EuroIntervention. 2012;8(3):336-344.

10. Takahashi S, Saito S, Tanaka S, Miyashita Y, Shiono T, Arai F, Domae H, et al. New method to increase a backup support of a 6 French guiding coronary catheter. Catheter Cardiovasc Interv. 2004;63(4):452-456.

11. Farooq V, Mamas MA, Fath-Ordoubadi F, Fraser DG. The use of a guide catheter extension system as an aid during transradial percutaneous coronary intervention of coronary artery bypass grafts. Catheter Cardiovasc Interv. 2011;78(6):847-863.

12. Brilakis ES, Banerjee S. Novel uses of the Proxis embolic protection catheter. Catheter Cardiovasc Interv. 2009;74(3):438-445.

13. Mamas MA, Fath-Ordoubadi F, Fraser D. Successful use of the Heartrail III catheter as a stent delivery catheter following failure of conventional techniques. Catheter Cardiovasc Interv. 2008;71(3):358-363.

14. Dursun H, Tastan A, Tanriverdi Z, Ozel E, Kaya D. GuideLiner catheter application in complex coronary lesions: experience of two centers. Anatol J Cardiol. 2016;16(5):333-339.

15. Ma M, Diao KY, Liu XJ, He Y. Early clinical experience with Guidezilla for transradial interventions in China. Sci Rep. 2018;8(1):5444.

16. Mozid AM, Davies JR, Spratt JC. The utility of a guideliner catheter in retrograde percutaneous coronary intervention of a chronic total occlusion with reverse cartthe "capture" technique. Catheter Cardiovasc Interv. 2014;83(6):929-932.

17. Waggoner T, Desai H, Sanghvi K. A unique complication of the GuideZilla guide extension support catheter and the risk of stent stripping in interventional \& endovascular interventions. Indian Heart J. 2015;67(4):381384. 